\title{
MicroRNA-Specificity Protein (Sp) Transcription Factor Interactions and Significance in Carcinogenesis
}

\author{
Stephen Safe
}

Published online: 11 January 2015

(C) Springer International Publishing AG 2015

\begin{abstract}
Specificity protein (Sp) transcription factors (TFs) such as Sp1, Sp3, and Sp4 are overexpressed in tumors, and $\mathrm{Sp} 1$ is a negative prognostic factor for multiple tumor types. Sp TFs regulate the expression of pro-oncogenic factors important for cell proliferation, survival, angiogenesis, migration/invasion, and inflammation, and the high expression of Sp TFs in tumors is primarily due to microRNAs (miRNAs). For example, expression of tumor-suppressor-like miRNAs such as miR-200b/ c, miR-335, miR-22, miR-149, and others that inactivate Sp1 expression is low in many tumor types. Research in our laboratory has also demonstrated that high expression of Sp TFs is also due to miRNA-dependent inhibition of the transcriptional repressors ZBTB10 and ZBTB4 by miR-27a and miR-20a/miR$17 \mathrm{p}$, respectively. Thus, miRNAs play a critical role in maintaining high levels of Sp1, Sp3, Sp4, and pro-oncogenic Spregulated genes in tumors and cancer cells, and there is ample evidence that anticancer agents targeting the miRNA-Sp TF axis can be highly effective for cancer chemotherapy.
\end{abstract}

Keywords Specificity protein transcription factors (Sp TFs) . Sp1 - Sp3 - Sp4 - miRNAs inhibit Sp TFs - miR-27a:ZBT10 . miR-20a/miR-17-5p:ZBTB4 $\cdot$ Sp TFs regulation

\section{Introduction}

With the advent of high throughput genome sequencing and annotation technologies, the increasing significance of non-

This article is part of the Topical Collection on miRNA and Cancer Prevention and Therapeutic Agents

S. Safe $(\triangle)$

Department of Veterinary Physiology and Pharmacology, Texas

A\&M University, 4466 TAMU, College Station, TX 77843-4466,

USA

e-mail: ssafe@cvm.tamu.edu protein encoding RNAs (ncRNAs) in cellular homeostasis and disease has become apparent [1-9]. Long non-coding RNAs (lncRNAs) contain $>200$ nucleotides, and recent reports from the ENCODE Project Consortium have identified 9277 lncRNA genes that produce 14,880 transcripts [10]. The biological roles of only a small fraction of lncRNAs have been reported, but it is apparent that they exhibit multiple functions and contribute to cellular homeostasis and diseases including cancer [3-5]. LncRNAs can interact with RNA, DNA, and proteins, and their mechanisms of action include their activity as decoys and guides that titrate away or guide proteins to their presumptive DNA targets, respectively [3, 4]. MicroRNAs (miRNAs, miRs) are small non-coding RNAs containing 21-23 nucleotides that primarily repress gene expression, and it has been estimated that there are in excess of 2500 human miRNAs that regulate the expression and the related functions of over $50 \%$ of the human genome [8]. Among noncoding RNAs, miRNAs have been most extensively investigated, and their regulation and function in maintaining cellular homeostasis and their role in diseases, particularly cancer, have been extensively investigated [6-8]. For example, miR143/145 exhibit tumor suppressor-like activity and are downregulated in multiple tumors. Mice with deletion of miR-143/ 145 exhibit defective epithelial regeneration after injury and this was linked to derepression of a critical miRNA target insulin-like growth factor binding protein 5 [11]. MiR-21 has been extensively identified as an oncogenic miRNA, and in mouse models, it has been shown that overexpression or knockdown of miR-21 enhances or inhibits lung tumorigenesis, respectively [12].

MiRNA interactions with target messenger RNAs (mRNAs) are dependent on specific base pair interactions of miRNAs with complementary 3 '-UTR sequences in targeted mRNAs. These interactions usually involved interactions of $\geq 6$ seed sequence oligonucleotides of the miRNA with complementary 3'-UTRs of targeted mRNAs, and several 
computational methods have been used to predict mRNA targets and the ranking of potential targets. The major problem associated with identification and characterization of a miRNA that regulates a specific mRNA and its resulting gene product is that most miRNAs can potentially target $\geq 300$ mRNAs [reviewed in [8]]. Moreover, every gene can potentially be regulated by multiple miRNAs. Thus, the common cellular approaches such as miRNA overexpression and knockdown used to study the targets and function of miRNAs must be interpreted cautiously due to modulation of more than one pathway that could affect multiple genes/ pathways and functions.

\section{Regulation of Specificity Proteins Transcription Factors by miRNAs in Cancer}

Specificity Proteins Transcription Factors and Cancer Specificity proteins (Sp) transcription factors (TFs) $\mathrm{Sp} 1, \mathrm{Sp} 3$, and Sp4 are highly expressed in most cancer cells/ tumors [13-20], and $\mathrm{Sp} 1$ is a negative prognostic factor for survival of glioma, pancreatic, and gastric cancer patients [21-24]. Although Sp1 and other Sp proteins are important for early embryonic and postnatal development in mice, their expression is relatively low in adult tissue, and there is evidence that $\mathrm{Sp} 1$ expression decreases with age in rodents and humans [25-27]. The functional importance of Sp1, Sp3, and Sp4 in cancer cells has been confirmed by RNAi, showing that knockdown (singly or combined) decreases cell proliferation, survival, angiogenesis, and inflammation. These results are consistent with identification (by RNAi) of several prooncogenic Sp-regulated genes important for cell growth (cyclin D1, EGFR, c-Met), survival (bcl-2, survivin), angiogenesis (VEGF, VEGF receptors [VEGFR]), and inflammation (p65-NFkB) [13-20]. Thus, Sp TFs clearly contribute to the transformed cell phenotype and represent an example of nononcogene addiction by cancer cells [28].

Regulation of Sp TFs by miRNAs: Inhibition Since Sp1 and other Sp TFs (e.g., Sp3 and Sp4) are overexpressed in cancer cells and exhibit pro-oncogenic activities, miRNAs that interact with and suppress expression of these genes tend to exhibit tumor suppressor-like activities. Sp1 is overexpressed in gastric tumors and is a negative prognostic factor for patient survival $[22,23]$, and several studies show that miRNAs are important for regulation of $\mathrm{Sp} 1$ in gastric cancer cells [29-32]. For example, miR-200b and miR-200c are downregulated in gastric tumors and cancer cells, and higher levels of these miRs correlate with a good prognosis for patients [29]. Ectopic expression of miR-200b and miR-200c in gastric cancer cells inhibit their growth and invasion and these miRs target $\mathrm{Sp} 1$ and DNA methyltransferases. MiR-335 expression also decreases during tumor development and formation
[33-36], and low levels are detected in gastric cancer cell lines and low expression in tumors is associated with lymph node metastasis and other negative prognostic factors [30]. MiR-335 overexpression in gastric cell lines results in decreased proliferation and invasion, and both $\mathrm{Sp} 1$ and bcl-2 have been identified as targets of miR-335 [30]. MiR-22 expression is also low in gastric tumors compared to nontumor tissue; miR-22 expression inhibits gastric cancer cell invasion and proliferation and Sp1 is a direct target of miR-22 [31]. Moreover, there is an inverse linear correlation between expression of miR-22 and Sp1 mRNA in gastric tumors. A recent study further extended the inhibitory miR-Sp1 interaction in gastric cancers by identifying miR-145, miR-133a, and miR-133b as miRs that also target $\mathrm{Sp} 1$ in gastric cancer cell lines [32]. Results of overexpression studies showed that this set of miRs also inhibits gastric cancer cell proliferation and invasion and this is due, in part, to the downregulation of Sp1regulated genes such as matrix metalloproteinase- 9 and cyclin D1.

MiR-429 expression is lower in esophageal tumors than in non-tumor tissue and low expression is significantly associated with increased lymph node metastasis [37]. Overexpression of miR-429 in esophageal cancer cell lines increases apoptosis and decreases migration, and miR-249 also binds 3'-UTR regions of both Sp1 and bcl-2 [37]. MiR$29 \mathrm{~b}$ interacts with $\mathrm{Sp} 1$ in both acute myeloid leukemia and multiple myeloma cells [38-40]. Sp1 and NF $\kappa B$ activate the KIT gene in acute myeloid leukemia cells which in turn results in MYC-dependent repression of miR-29b. Decreased expression of miR-29b results in increased levels of Sp1 since miR$29 \mathrm{~b}$ targets (downregulates) Sp1 [38]. In addition, Sp/HDAC/ NFKB also inhibit miR-29b expression, and this complex regulatory system that drives KIT expression can be targeted in vivo by overexpression of miR-29b (as a nanoparticle complex), which results in a marked decrease in expression of Sp1 and other miR-29b targets [39]. Sp1 is also a negative regulator of miR-29b in multiple myeloma cells but miR-29b expression also decreases Sp1 protein in these cells [40], suggesting a regulator loop similar to that observed in acute myeloid leukemia cells.

MiR-375 expression is decreased in cervical tumors compared to non-tumor tissue and low expression in tumors is a negative prognostic factor for cervical cancer patients [41]. Overexpression of miR-375 decreases cervical cancer cell proliferation, migration, and invasion and downregulates Sp1 (protein) expression, and Sp1 knockdown and miR-375 overexpression results in similar functional responses [41]. Similar studies in prostate cancer cells with miR-330 [42] and colon cancer cells (miR-149) [43] showed that both miRs exhibit tumor-suppressor-like activity (inhibition of cell growth and invasion) and downregulate Sp1. CD147 is overexpressed in breast tumors and is associated with tumor progression and this gene is regulated by $\mathrm{Sp} 1$ and $\mathrm{cMyc}$. MiR- 
22 decreases CD147 expression through targeting Sp1, and the tumor-suppressor-like activity of miR-22 is due, in part, to downregulation of Sp1 [44].

These results as illustrated in Fig. 1a clearly demonstrate that miRNAs play a critical role in regulating $\mathrm{Sp} 1$ expression in several cancer cell types and corresponding tumors and suggest that the high expression and pro-oncogenic functions of Sp1 in multiple cancers are due, in part, to decreased expression of tumor-suppressor-like miRNAs that target $\mathrm{Sp} 1$. The inverse relationship between levels of miRNAs 200b, 200c, 335, 22, 145, 133a, 133b, 429, 29b, 375, 330, and 149 and Sp1 suggests that drugs targeting Sp1 or inducing these miRs may be important therapeutic avenues for cancer chemotherapy. All previous studies have focused primarily on $\mathrm{Sp} 1$; however, there is evidence that in some cancer cells, Sp3 and Sp4 have similar pro-oncogenic activities that should also be considered and further investigated [45].

Indirect Regulation of Sp TFs by miRNAs Studies in this laboratory reported that $\mathrm{Sp} 1, \mathrm{Sp} 3$, and $\mathrm{Sp} 4$ are overexpressed in breast cancer cell lines compared to non-transformed mammary cells, and the underlying mechanisms associated with high expression of $\mathrm{Sp} \mathrm{TFs} \mathrm{were} \mathrm{investigated} \mathrm{[46].} \mathrm{It} \mathrm{was}$ previously reported that miR-27a suppresses expression of ZBTB10 [47], which is a member of the POK family of transcriptional repressors [48, 49], and overexpression of

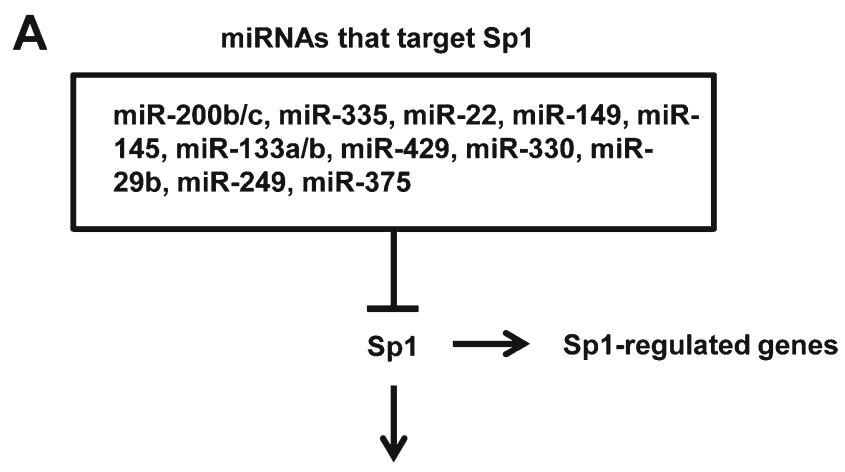

Negative Prognostic Factor

(gastric, pancreatic, glioma)

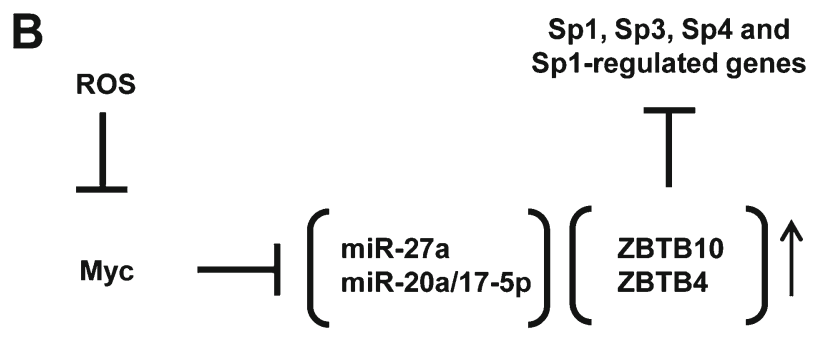

Fig. 1 a Sp1 levels are high in solid tumors due to the low expression of most miRNAs that suppress Sp1. b ROS decreases expression of Myc and Myc-related miRs to induce expression of Sp repressors (ZBTB10/ ZBTB4) that downregulate Sp1, Sp3, Sp4, and Sp-regulated genes [64•]
ZBTB10 decreased expression of the Sp-regulated gastrin gene [50]. Since miR-27a and associated members of the miR-23a $\sim$ miR-27a miR-24-2 cluster are overexpressed in multiple cancer cell lines and tumors [46, 51-53], we further investigated the role of miR-27a-mediated suppression of ZBTB10 as a mechanism for maintaining high levels of Sp1, Sp3, and Sp4 in breast cancer cells [46]. Transfection of breast cancer cells with miR-27a antagomirs increased the expression of ZBTB10 and decreased the levels of Sp1, Sp3, Sp4, and pro-oncogenic Sp-regulated gene products, and similar results were observed after overexpression of ZBTB10 in breast cancer cell lines. Not surprisingly, miR-27 antagomirs also induced apoptosis and inhibited breast cancer cell growth and cell cycle progression, and this was due not only to ZBTB10-mediated repression of Sp TFs and Sp-regulated genes but also activation of Myt-1 which inhibited cells at the $\mathrm{G} 2 / \mathrm{M}$ phase of the cell cycle. The role of miR27a:ZBTB10 in the maintenance of high levels of Sp1, Sp3, and Sp4 has been observed in breast, pancreatic, colon, rhabdomyosarcoma, and bladder cancer cell lines [13-15, 46, 51-61].

We also examined breast cancer patient array data bases for expression of ZBTB family members and identified ZBTB4 as a prognostic factor in which high or low expression predicts increased or decreased relapse-free survival, respectively [62]. The NCI-60 cell mRNA and miRNA data sets were used to examine possible inverse correlations between ZBTB4 expression and miRs, and several miRNAs that could potentially target ZBTB4 were identified. These included members of miR-17-92 (miR-20a and miR-17-5p) and miR-106b-25 (miR-106 and miR-93) clusters which have identical seed sequences. Subsequent studies showed that ZBTB4 overexpression or miR antagomirs decreased the expression of Sp1, Sp3, Sp4, and Sp-regulated genes in breast, bladder, and prostate cancer cells $[57,62,63 \bullet]$, confirming that miR-20a and paralogs suppress ZBTB4 and this also contributes to the high expression of Sp TFs in cancer cell lines. A recent study also showed that miR-20a/miR-17-5p-mediated suppression of ZBTB4 also contributed to high Sp expression in pancreatic cancer cells and ZBTB4 expression also downregulated Sp1, $\mathrm{Sp} 3$, and Sp4 [64•]. These studies demonstrate a critical role for miR:ZBTB interactions in maintaining high levels of $\mathrm{Sp}$ proteins and pro-oncogenic Sp-regulated genes in cancer cell lines (Fig. 1b), and therefore, these miRs are potential drug targets for cancer chemotherapy.

Drugs that Target miR:ZBTB Decrease Sp TFs The list of anticancer agents that downregulate $\mathrm{Sp} 1, \mathrm{Sp} 3$, and Sp4 is continually expanding and includes clinically used compounds such as arsenic trioxide, bortezomib, metformin, several non-steroidal anti-inflammatory drugs (NSAIDs) including aspirin and tolfenamic acid, curcumin, naturally occurring and synthetic triterpenoids, other natural products, and 
reactive oxygen species (ROS)-inducing compounds [13-20, 54-62, 63•, 64•, 65-69] . Our studies show that Sp proteins are downregulated via two major pathways, namely, Sp protein degradation (proteasomes and caspases) and repression of $\mathrm{Sp} 1, \mathrm{Sp} 3$, and Sp4 gene expression. At least one of the gene repression pathways has been characterized and this explains the mechanism of ROS-mediated downregulation of Sp1, Sp3, and Sp4 (Fig. 1b) [45]. A recent study reported that hydrogen peroxide rapidly decreased the expression of cMYC and several other genes in colon cancer cells and this was due to genome-wide shifts of chromatin-modifying repressor complexes from non-GC-rich to GC-rich sites [70]. Studies in this laboratory have now demonstrated that ROS inducers such as phenethylisothiocyanate (PEITC) rapidly decrease cMYC expression in pancreatic cancer cells, and cMYC regulates both miR-27a and miR-20a/miR-17-5p expression which is also decreased in pancreatic cancer cells by PEITC [64•]. Moreover, knockdown of cMYC by RNA interference decreases the expression of miR-27a and miR-20a/ 17-5p; induces ZBTB10 and ZBTB4; and downregulates Sp1, $\mathrm{Sp} 3$, Sp4, and pro-oncogenic Sp-regulated genes. These results clearly demonstrate that another important function of MYC in cancer cells is the maintenance of high levels of Sp TFs due to the regulation of miRs that in turn inhibit expression of the Sp-repressors ZBTB10 and ZBTB4.

Sp Regulation of miRs Since Sp TFs regulate multiple genes in breast cancer cells, it is not surprising that they also regulate expression of miRNAs. For example, the miR-200b 200a 429 minimal promoter contains several GC-rich Sp binding sites that are important for the high expression of this miRNA cluster in breast cancer cells, and knockdown of Sp1 by RNAi decreases the expression of members of this miRNA cluster [71]. There is also evidence that $\mathrm{Sp} 1$ regulates the expression of the pro-oncogenic miR-17-92 cluster in cancer cell lines and Sp1 plays a role in the expression of miR-365, which in turn suppresses interleukin $6[72,73]$. Ongoing studies in this laboratory indicate that $\mathrm{Sp} 1, \mathrm{Sp} 3$, and $\mathrm{Sp} 4$ regulate other miRNAs and long non-coding RNAs, suggesting that these non-coding RNAs are also potential targets for agents that downregulate Sp TFs.

\section{Conclusions}

MiRNAs play an integral role in maintaining cellular homeostasis and in disease, and this is particularly true in cancer. MiRs exhibit both oncogenic and tumor-suppressor-like activity and there is great potential for using miRNAs as direct drug targets. Serum levels of miRs are emerging as potential prognostic factors and potential indicators of drug efficacy, and drug-induced downregulation of miRs could be observed in serum and be a marker of treatment efficacy. An important functional component of miRs is their linkage to the direct and indirect regulation of $\mathrm{Sp} 1, \mathrm{Sp} 3, \mathrm{Sp} 4$, and pro-oncogenic $\mathrm{Sp}$ regulated genes in cancer cells and tumors. Sp TFs are prototypical examples of non-oncogene addition by cancer cells, and development of ROS-inducing anticancer agents that target these factors is also dependent, in part, on miRs, particularly those that are regulated by $\mathrm{cMYC}[74,75]$.

Acknowledgments The funding support of the Syd Kyle Endowment and the National Institutes of Health (P30ES023512) is gratefully acknowledged.

\section{Compliance with Ethics Guidelines}

Conflict of Interest Stephen Safe declares that he has no conflict of interest.

Human and Animal Rights and Informed Consent This article does not contain any studies with human or animal subjects performed by the author.

\section{References}

Papers of particular interest, published recently, have been highlighted as:

- Of importance

1. Szymanski M, Barciszewski J. Beyond the proteome: non-coding regulatory RNAs. Genome Biol. 2002;3:reviews0005.

2. Prasanth KV, Spector DL. Eukaryotic regulatory RNAs: an answer to the 'genome complexity' conundrum. Genes Dev. 2007;21:1142.

3. Rinn JL, Chang HY. Genome regulation by long noncoding RNAs. Annu Rev Biochem. 2012;81:145-66.

4. Wang KC, Chang HY. Molecular mechanisms of long noncoding RNAs. Mol Cell. 2011;43:904-14.

5. Huarte M, Rinn JL. Large non-coding RNAs: missing links in cancer? Hum Mol Genet. 2010;19:R152-61.

6. Kong YW, Ferland-McCollough D, Jackson TJ, Bushell M. microRNAs in cancer management. Lancet Oncol. 2012;13:e249 58.

7. Mendell JT, Olson EN. MicroRNAs in stress signaling and human disease. Cell. 2012;148:1172-87.

8. Hayes J, Peruzzi PP, Lawler S. MicroRNAs in cancer: biomarkers, functions and therapy. Trends Mol Med 2014.

9. Cech TR, Steitz JA. The noncoding RNA revolution-trashing old rules to forge new ones. Cell. 2014;157:77-94.

10. Derrien T, Johnson R, Bussotti G, Tanzer A, Djebali S, Tilgner H, et al. The GENCODE v7 catalog of human long noncoding RNAs: analysis of their gene structure, evolution, and expression. Genome Res. 2012;22:1775-89.

11. Chivukula RR, Shi G, Acharya A, Mills EW, Zeitels LR, Anandam $\mathrm{JL}$, et al. An essential mesenchymal function for miR-143/145 in intestinal epithelial regeneration. Cell. 2014;157:1104-16.

12. Hatley ME, Patrick DM, Garcia MR, Richardson JA, Bassel-Duby R, van Rooij E, et al. Modulation of K-Ras-dependent lung tumorigenesis by MicroRNA-21. Cancer Cell. 2010;18:282-93. 
13. Chintharlapalli S, Papineni S, Abdelrahim M, Abudayyeh A, Jutooru I, Chadalapaka G, et al. Oncogenic microRNA-27a is a target for anticancer agent methyl 2-cyano-3,11-dioxo-18betaolean-1,12-dien-30-oate in colon cancer cells. Int $\mathrm{J}$ Cancer. 2009;125:1965-74.

14. Chadalapaka G, Jutooru I, Sreevalsan S, Pathi S, Kim K, Chen C, et al. Inhibition of rhabdomyosarcoma cell and tumor growth by targeting specificity protein (Sp) transcription factors. Int J Cancer. 2013;132:795-806.

15. Liu X, Jutooru I, Lei P, Kim K, Lee SO, Brents LK, et al. Betulinic acid targets YY1 and ErbB2 through cannabinoid receptordependent disruption of microRNA-27a:ZBTB10 in breast cancer. Mol Cancer Ther. 2012;11:1421-31.

16. Papineni S, Chintharlapalli S, Abdelrahim M, Lee SO, Burghardt R, Abudayyeh A, et al. Tolfenamic acid inhibits esophageal cancer through repression of specificity proteins and c-Met. Carcinogenesis. 2009;30:1193-201.

17. Chadalapaka G, Jutooru I, Burghardt R, Safe S. Drugs that target specificity proteins downregulate epidermal growth factor receptor in bladder cancer cells. Mol Cancer Res. 2010;8:739-50.

18. Chintharlapalli S, Papineni S, Lee SO, Lei P, Jin UH, Sherman SI, et al. Inhibition of pituitary tumor-transforming gene-1 in thyroid cancer cells by drugs that decrease specificity proteins. Mol Carcinog. 2011;50:655-67.

19. Chintharlapalli S, Papineni S, Ramaiah SK, Safe S. Betulinic acid inhibits prostate cancer growth through inhibition of specificity protein transcription factors. Cancer Res. 2007;67:2816-23.

20. Abdelrahim M, Baker CH, Abbruzzese JL, Safe S. Tolfenamic acid and pancreatic cancer growth, angiogenesis, and Sp protein degradation. J Natl Cancer Inst. 2006;98:855-68.

21. Guan H, Cai J, Zhang N, Wu J, Yuan J, Li J, et al. Sp1 is upregulated in human glioma, promotes MMP-2-mediated cell invasion and predicts poor clinical outcome. Int J Cancer. 2012;130:593-601.

22. Wang L, Wei D, Huang S, Peng Z, Le X, Wu TT, et al. Transcription factor $\mathrm{Sp} 1$ expression is a significant predictor of survival in human gastric cancer. Clin Cancer Res. 2003;9:6371-80.

23. Yao JC, Wang L, Wei D, Gong W, Hassan M, Wu TT, et al. Association between expression of transcription factor Sp1 and increased vascular endothelial growth factor expression, advanced stage, and poor survival in patients with resected gastric cancer. Clin Cancer Res. 2004;10:4109-17.

24. Jiang NY, Woda BA, Banner BF, Whalen GF, Dresser KA, Lu D. Sp1, a new biomarker that identifies a subset of aggressive pancreatic ductal adenocarcinoma. Cancer Epidemiol Biomarkers Prev. 2008; $17: 1648-52$.

25. Ammendola R, Mesuraca M, Russo T, Cimino F. Sp1 DNA binding efficiency is highly reduced in nuclear extracts from aged rat tissues. J Biol Chem. 1992;267:17944-8.

26. Adrian GS, Seto E, Fischbach KS, Rivera EV, Adrian EK, Herbert DC, et al. YY1 and Sp1 transcription factors bind the human transferrin gene in an age-related manner. J Gerontol A Biol Sci Med Sci. 1996;51:B66-75.

27. Oh JE, Han JA, Hwang ES. Downregulation of transcription factor, Sp1, during cellular senescence. Biochem Biophys Res Commun. 2007;353:86-91.

28. Luo J, Solimini NL, Elledge SJ. Principles of cancer therapy: oncogene and non-oncogene addiction. Cell. 2009;136:823-37.

29. Tang H, Deng M, Tang Y, Xie X, Guo J, Kong Y, et al. miR-200b and miR-200c as prognostic factors and mediators of gastric cancer cell progression. Clin Cancer Res. 2013;19:5602-12.

30. Xu Y, Zhao F, Wang Z, Song Y, Luo Y, Zhang X, et al. MicroRNA335 acts as a metastasis suppressor in gastric cancer by targeting Bcl-w and specificity protein 1. Oncogene. 2012;31:1398-407.

31. Guo MM, Hu LH, Wang YQ, Chen P, Huang JG, Lu N, et al. miR22 is down-regulated in gastric cancer, and its overexpression inhibits cell migration and invasion via targeting transcription factor Sp1. Med Oncol. 2013;30:542.

32. Qiu T, Zhou X, Wang J, Du Y, Xu J, Huang Z, et al. MiR-145, miR133a and miR-133b inhibit proliferation, migration, invasion and cell cycle progression via targeting transcription factor $\mathrm{Sp} 1$ in gastric cancer. FEBS Lett. 2014;588:1168-77.

33. Wang YX, Zhang XY, Zhang BF, Yang CQ, Chen XM, Gao HJ. Initial study of microRNA expression profiles of colonic cancer without lymph node metastasis. J Dig Dis. 2010;11:50-4.

34. Marcucci G, Maharry K, Radmacher MD, Mrozek K, Vukosavljevic T, Paschka P, et al. Prognostic significance of, and gene and microRNA expression signatures associated with, CEBPA mutations in cytogenetically normal acute myeloid leukemia with highrisk molecular features: a Cancer and Leukemia Group B Study. J Clin Oncol. 2008;26:5078-87.

35. Soon PS, Tacon LJ, Gill AJ, Bambach CP, Sywak MS, Campbell PR, et al. miR-195 and miR-483-5p identified as predictors of poor prognosis in adrenocortical cancer. Clin Cancer Res. 2009;15: 7684-92.

36. Sorrentino A, Liu CG, Addario A, Peschle C, Scambia G, Ferlini C. Role of microRNAs in drug-resistant ovarian cancer cells. Gynecol Oncol. 2008;111:478-86.

37. Wang Y, Li M, Zang W, Ma Y, Wang N, Li P, et al. MiR-429 upregulation induces apoptosis and suppresses invasion by targeting Bcl-2 and SP-1 in esophageal carcinoma. Cell Oncol (Dordr). 2013;36:385-94.

38. Liu S, Wu LC, Pang J, Santhanam R, Schwind S, Wu YZ, et al. Sp1/ NFkappaB/HDAC/miR-29b regulatory network in KIT-driven myeloid leukemia. Cancer Cell. 2010;17:333-47.

39. Huang X, Schwind S, Yu B, Santhanam R, Wang H, Hoellerbauer P, et al. Targeted delivery of microRNA-29b by transferrin-conjugated anionic lipopolyplex nanoparticles: a novel therapeutic strategy in acute myeloid leukemia. Clin Cancer Res. 2013;19:2355-67.

40. Amodio N, Di Martino MT, Foresta U, Leone E, Lionetti M, Leotta $\mathrm{M}$, et al. miR-29b sensitizes multiple myeloma cells to bortezomibinduced apoptosis through the activation of a feedback loop with the transcription factor Sp1. Cell Death Dis. 2012;3:e436.

41. Wang F, Li Y, Zhou J, Xu J, Peng C, Ye F, et al. miR-375 is downregulated in squamous cervical cancer and inhibits cell migration and invasion via targeting transcription factor SP1. Am J Pathol. 2011;179:2580-8.

42. Mao Y, Chen H, Lin Y, Xu X, Hu Z, Zhu Y, et al. microRNA-330 inhibits cell motility by downregulating $\mathrm{Sp} 1$ in prostate cancer cells. Oncol Rep. 2013;30:327-33.

43. Wang F, Ma YL, Zhang P, Shen TY, Shi CZ, Yang YZ, et al. SP1 mediates the link between methylation of the tumour suppressor miR-149 and outcome in colorectal cancer. J Pathol. 2013;229:1224.

44. Kong LM, Liao CG, Zhang Y, Xu J, Li Y, Huang W, et al. A regulatory loop involving miR-22, Sp1, and c-Myc modulates CD147 expression in breast cancer invasion and metastasis. Cancer Res. 2014;74:3764-78.

45. Safe S, Imanirad P, Sreevalsan S, Nair V, Jutooru I. Transcription factor Sp1, also known as specificity protein 1 as a therapeutic target. Expert Opin Ther Targets. 2014;18:759-69.

46. Mertens-Talcott SU, Noratto GD, Li X, Angel-Morales G, Bertoldi MC, Safe S. Betulinic acid decreases ER-negative breast cancer cell growth in vitro and in vivo: role of $\mathrm{Sp}$ transcription factors and microRNA-27a:ZBTB10. Mol Carcinog 2012.

47. Scott GK, Mattie MD, Berger CE, Benz SC, Benz CC. Rapid alteration of microRNA levels by histone deacetylase inhibition. Cancer Res. 2006;66:1277-81.

48. Perez-Torrado R, Yamada D, Defossez PA. Born to bind: the BTB protein-protein interaction domain. Bioessays. 2006;28:1194-202.

49. Costoya JA. Functional analysis of the role of POK transcriptional repressors. Brief Funct Genomic Proteomic. 2007;6:8-18. 
50. Tillotson LG. RIN ZF, a novel zinc finger gene, encodes proteins that bind to the CACC element of the gastrin promoter. J Biol Chem. 1999;274:8123-8.

51. Liu T, Tang H, Lang Y, Liu M, Li X. MicroRNA-27a functions as an oncogene in gastric adenocarcinoma by targeting prohibitin. Cancer Lett. 2009;273:233-42.

52. Wang Q, Li DC, Li ZF, Liu CX, Xiao YM, Zhang B, et al. Upregulation of miR-27a contributes to the malignant transformation of human bronchial epithelial cells induced by SV40 small T antigen. Oncogene. 2011;30:3875-86.

53. Ma Y, Yu S, Zhao W, Lu Z, Chen J. miR-27a regulates the growth, colony formation and migration of pancreatic cancer cells by targeting Sprouty2. Cancer Lett. 2010;298:150-8.

54. Jutooru I, Chadalapaka G, Abdelrahim M, Basha MR, Samudio I, Konopleva M, et al. Methyl 2-cyano-3,12-dioxooleana-1,9-dien28-oate decreases specificity protein transcription factors and inhibits pancreatic tumor growth: role of microRNA-27a. Mol Pharmacol. 2010;78:226-36.

55. Chintharlapalli S, Papineni S, Lei P, Pathi S, Safe S. Betulinic acid inhibits colon cancer cell and tumor growth and induces proteasome-dependent and -independent downregulation of specificity proteins (Sp) transcription factors. BMC Cancer. 2011;11:371.

56. Pathi SS, Jutooru I, Chadalapaka G, Sreevalsan S, Anand S, Thatcher GR, et al. GT-094, a NO-NSAID, inhibits colon cancer cell growth by activation of a reactive oxygen species-microRNA27a: ZBTB10-specificity protein pathway. Mol Cancer Res. 2011;9: 195-202.

57. Chadalapaka G, Jutooru I, Safe S. Celastrol decreases specificity proteins ( $\mathrm{Sp}$ ) and fibroblast growth factor receptor-3 (FGFR3) in bladder cancer cells. Carcinogenesis. 2012;33:886-94

58. Sreevalsan S, Safe S. The cannabinoid WIN 55,212-2 decreases specificity protein transcription factors and the oncogenic cap protein eIF4E in colon cancer cells. Mol Cancer Ther. 2013;12:248393.

59. Nair V, Pathi S, Jutooru I, Sreevalsan S, Basha R, Abdelrahim M, et al. Metformin inhibits pancreatic cancer cell and tumor growth and downregulates $\mathrm{Sp}$ transcription factors. Carcinogenesis. 2013;34:2870-9.

60. Gandhy SU, Kim K, Larsen L, Rosengren RJ, Safe S. Curcumin and synthetic analogs induce reactive oxygen species and decreases specificity protein $(\mathrm{Sp})$ transcription factors by targeting microRNAs. BMC Cancer. 2012;12:564.

61. Safe SH, Prather PL, Brents LK, Chadalapaka G, Jutooru I. Unifying mechanisms of action of the anticancer activities of triterpenoids and synthetic analogs. Anticancer Agents Med Chem. 2012;12:1211-20.

62. Kim K, Chadalapaka G, Pathi SS, Jin UH, Lee JS, Park YY, et al. Induction of the transcriptional repressor ZBTB4 in prostate cancer cells by drug-induced targeting of microRNA-17-92/106b-25 clusters. Mol Cancer Ther. 2012;11:1852-62.

63. Kim K, Chadalapaka G, Lee SO, Yamada D, Sastre-Garau X, Defossez PA, et al. Identification of oncogenic microRNA-17-92/ ZBTB4/specificity protein axis in breast cancer. Oncogene.
2012;31:1034-44. This paper demonstrates for the first time that members of the oncogenic miR-17-92 complex suppress expression of ZBTB4 and this facilitates high expression of Sp transcription factors in cancer cells.

64. Jutooru I, Guthrie AS, Chadalapaka G, Pathi S, Kim K, Burghardt R, et al. Mechanism of action of phenethylisothiocyanate and other reactive oxygen species-inducing anticancer agents. Mol Cell Biol. 2014;34:2382-95. This study shows that ROS-dependent suppression of cMyc results in decreased expression of Sp transcription factors through disruption of miR-ZBTB (transcriptional repressors) interactions in cancer cells.

65. Pathi SS, Lei P, Sreevalsan S, Chadalapaka G, Jutooru I, Safe S. Pharmacologic doses of ascorbic acid repress specificity protein (Sp) transcription factors and $\mathrm{Sp}$-regulated genes in colon cancer cells. Nutr Cancer. 2011;63:1133-42.

66. Chadalapaka G, Jutooru I, Chintharlapalli S, Papineni S, Smith 3rd $\mathrm{R}, \mathrm{Li} \mathrm{X}$, et al. Curcumin decreases specificity protein expression in bladder cancer cells. Cancer Res. 2008;68:5345-54.

67. Jutooru I, Chadalapaka G, Lei P, Safe S. Inhibition of NFkappaB and pancreatic cancer cell and tumor growth by curcumin is dependent on specificity protein down-regulation. J Biol Chem. 2010;285: 25332-44.

68. Jutooru I, Chadalapaka G, Sreevalsan S, Lei P, Barhoumi R, Burghardt R, et al. Arsenic trioxide downregulates specificity protein $(\mathrm{Sp})$ transcription factors and inhibits bladder cancer cell and tumor growth. Exp Cell Res. 2010;316:2174-88.

69. Abdelrahim M, Baker CH, Abbruzzese JL, Sheikh-Hamad D, Liu S, Cho SD, et al. Regulation of vascular endothelial growth factor receptor- 1 expression by specificity proteins 1,3 , and 4 in pancreatic cancer cells. Cancer Res. 2007;67:3286-94.

70. O'Hagan HM, Wang W, Sen S, Destefano Shields C, Lee SS, Zhang $\mathrm{YW}$, et al. Oxidative damage targets complexes containing DNA methyltransferases, SIRT1, and polycomb members to promoter CpG Islands. Cancer Cell. 2011;20:606-19.

71. Kolesnikoff N, Attema JL, Roslan S, Bert AG, Schwarz QP, Gregory PA, et al. Specificity protein 1 (Sp1) maintains basal epithelial expression of the miR-200 family: implications for epithelial-mesenchymal transition. J Biol Chem. 2014;289:11194 205.

72. Ji M, Rao E, Ramachandrareddy H, Shen Y, Jiang C, Chen J, et al. The miR-17-92 microRNA cluster is regulated by multiple mechanisms in B-cell malignancies. Am J Pathol. 2011;179:1645-56.

73. Xu Z, Xiao SB, Xu P, Xie Q, Cao L, Wang D, et al. miR-365, a novel negative regulator of interleukin- 6 gene expression, is cooperatively regulated by Sp1 and NF-kappaB. J Biol Chem. 2011;286:2140112.

74. Xiong L, Jiang W, Zhou R, Mao C, Guo Z. Identification and analysis of the regulatory network of Myc and microRNAs from high-throughput experimental data. Comput Biol Med. 2013;43: 1252-60.

75. Frenzel A, Loven J, Henriksson MA. Targeting MYC-regulated miRNAs to combat cancer. Genes Cancer. 2010;1:660-7. 